\title{
Erratum to: Haitian Adolescent Personality Clusters and Their Problem Area Correlates
}

\author{
Robert C. McMahon - Vaughn E. Bryant • \\ Jessy G. Dévieux $\cdot$ Michèle Jean-Gilles · \\ Rhonda Rosenberg $\cdot$ Robert M. Malow
}

Published online: 13 March 2012

(C) Springer Science+Business Media, LLC 2012

\section{Erratum to: J Immigrant Minority Health DOI 10.1007/s10903-012-9584-8}

In the Results section, the following is incorrect:

Males represented 59\% of the total MACI sample and were underrepresented in Cluster $1(46 \%)$ and overrepresented in Cluster $3(67 \%) 57 \%$ of Cluster 3 participants were male. Females made up $41 \%$ of the total sample and were underrepresented in Cluster $2(32 \%)$ and overrepresented in Cluster 3 (53\%) $\left(\chi^{2}=7.33(2), p=.026\right)$.
The corrected text should read:

Males represented $32.4 \%$ of the total MACI sample and were underrepresented in Cluster 1 (23.5\%) and overrepresented in Cluster 3 (38.7\%). Females made up 67.6\% of the total sample and were underrepresented in Cluster $2(30 \%)$ and overrepresented in Cluster $1(76.4 \%)\left(\chi^{2}=4.51(1)=.034\right)$.

In Table 2, in the column titled 'Tukey HSD Comparison', the third row reflecting POSIT Mental Health Scale comparison is incorrect: $2>3>1$ and must be replaced by $2>1>3$.

The online version of the original article can be found under doi:10.1007/s10903-012-9584-8.

\section{R. C. McMahon}

Department of Educational and Psychological Studies,

University of Miami, Miami, FL, USA

V. E. Bryant $(\bowtie) \cdot$ J. G. Dévieux · M. Jean-Gilles ·

R. Rosenberg · R. M. Malow

Department of Health Promotion and Disease Prevention,

Robert Stempel College of Public Health and Social Work,

AIDS Prevention Program, Florida International University,

3000 NE 151st St., North Miami, FL 33181, USA

e-mail: vebryant@smcm.edu 